\title{
Quorum-sensing-deficient (lasR) mutants emerge at high frequency from a Pseudomonas aeruginosa mutS strain
}

\author{
Adela M. Luján, Alejandro J. Moyano, Ignacio Segura, Carlos E. Argaraña \\ and Andrea M. Smania
}

Correspondence

Andrea M. Smania

asmania@mail.fcq.unc.edu.ar

Received 24 March 2006

Revised 8 August 2006

Accepted 21 September 2006
Centro de Investigaciones en Química Biológica de Córdoba (CIQUIBIC), CONICET, Departamento de Química Biológica, Facultad de Ciencias Químicas, Universidad Nacional de Córdoba, Haya de la Torre y Medina Allende, Ciudad Universitaria, X5000HUA, Córdoba, Argentina

In Pseudomonas aeruginosa, quorum sensing constitutes a highly complex cell-to-cell communication system that, along with the cognate acylhomoserine lactone signals and regulators LasR and RhIR, modulates the production of virulence factors and a wide range of metabolic functions. In a previous paper, the authors reported that mismatch repair disruption in $P$. aeruginosa results in the spontaneous and reproducible emergence of defined morphological colony variants after a relatively short period of cultivation in an aerated rich medium, in contrast to the non-mutator parental strain, which does not display any kind of diversification under identical incubation conditions. One of the morphotypical variants, $\mathrm{mS} 2$, emerges at a high frequency and displays differences in virulence traits that could be regulated by major quorum-sensing regulators. The present study shows that $m u t S$ mS2 variants had defective LasR function due to simple but different point mutations along the las $R$ gene sequence, indicating that Las $R$ inactivation is the main cause of $\mathrm{mS} 2$ phenotypic diversification. Moreover, it was determined that a non-functional LasR would confer a selective advantage in the late stationary phase, since viability was notably higher for $\mathrm{mS} 2$. Interestingly, in all $\mathrm{mS} 2$ variants analysed, no sequence alterations were found in the gac $A$ and $r h / R$ genes, suggesting that the selective pressures for GacA/RhIR and LasR were not the same and differed from those in other Pseudomonas species, which, when incubated in nutrient-rich liquid stationary-phase cultures, show specific high instability in the gacA-gacS genes.

\section{INTRODUCTION}

Pseudomonas aeruginosa is a Gram-negative bacterium that has an extraordinarily versatile metabolic potential allowing it to survive in a number of natural and nosocomial environments. It is also an opportunistic human pathogen that infects injured, burned and immunodeficient patients and causes severe and often fatal chronic infection in cystic fibrosis (CF) patients (Lyczak et al., 2002). In addition, $P$. aeruginosa has remarkable versatility in its mechanisms of virulence, expressing and secreting a multiplicity of factors such as proteases, toxins, pigments and haemolysins that contribute to its survival and pathogenicity. The expression of these exoproducts is regulated, at least in part, by a cell-tocell signalling system known as quorum sensing (QS) that directs the activation of specific genes at high cell densities in response to chemical signals released by $P$. aeruginosa itself (Whiteley et al., 1999; Smith \& Iglewski, 2003a). P.

Abbreviations: AHL, N-acylhomoserine lactone; CF, cystic fibrosis; HSL, homoserine lactone; MMRS, mismatch repair system; POS, Pseudomonas quinolone signal; OS, quorum sensing. aeruginosa QS involves the transcriptional regulators LasR and RhlR and their respective autoinducer synthases, LasI and RhlI, which direct the synthesis of their cognate signal molecules 3-oxo-C12 and C4 homoserine lactones (HSL) (Smith \& Iglewski, 2003a). The two P. aeruginosa QS systems are linked, and operate in a hierarchical cascade, with the las system dominating over the rhl system at the transcriptional and posttranscriptional level (Pesci et al., 1997). A third signal molecule recently found to be involved in $P$. aeruginosa QS is the 2-heptyl-3-hydroxy-4-quinolone Pseudomonas quinolone signal (PQS), which provides a further link between the las and rhl systems since both of them control the synthesis of PQS, which in turn controls the expression of RhlR and RhlI (Pesci et al., 1999; McKnight et al., 2000). Likewise, the P. aeruginosa QS cascade is regulated by a variety of other regulatory systems with a high potential to integrate and respond to multiple environmental signals, thereby generating a very complex signalling network that constitutes one of the bases for its exceptional adaptability (Schuster \& Greenberg, 2006). One of these factors is GacA, a highly conserved two-component 
response regulator, which is generally responsible for the control of virulence factors, antibiotic production, biofilm formation and stress response in fluorescent pseudomonads (Parkins et al., 2001; Heeb \& Haas, 2001). In the $P$. aeruginosa regulatory hierarchy, GacA acts above LasR and RhlR, positively regulating the production of C4-HSL, pyocyanin, cyanide and lipase (Reimmann et al., 1997). In addition, the complex QS signalling circuitry includes, among others, the sigma factors RpoS and RpoN, the LuxR homologues QscR and VqsR, and global transcriptional regulators such as AlgQ, MvaT, DksA and VfR (Schuster \& Greenberg, 2006).

As in other bacterial species that develop in constantly changing environments, the adaptability of $P$. aeruginosa has been linked to the high frequency of clones with high mutation rates (mutators) (for a review see Denamour \& Matic, 2006). Mutator phenotypes generally result from alterations in genes encoding DNA repair enzymes and for proteins that assure the accuracy of DNA replication. One of the main DNA repair systems in bacteria is the mismatch repair system (MMRS), which monitors the fidelity of DNA replication by repairing DNA polymerase errors and blocks homologous recombination events (Kunkel \& Erie, 2005). As a consequence, MMRS-defective bacteria show both a mutator and a hyperecombinogenic phenotype. Interestingly, it has been observed that $P$. aeruginosa mutator clones are extremely frequent in chronic CF lung infections but not in acute infections (Oliver et al., 2000), suggesting that they play a crucial role in the adaptation required for long-term establishment in the heterogeneous and changing CF lung environment. It is important to mention that most of these mutator strains were found to be deficient in the MMRS with mutations in one of the main components of the system, the mutS gene (Oliver et al., 2002). $P$. aeruginosa isolated from CF patients also differ from those obtained from acute infections, in that they show significant phenotypic variation, displaying a wide spectrum of morphotypic colony variants (Martin et al., 1995; Oliver et al., 2000). In a previous paper (Smania et al., 2004), we described a mutator $P$. aeruginosa Hex1T mutS mutant strain which, if grown to late stationary phase, spontaneously gives rise to diverse colony morphologies, in contrast to the parental non-mutator (wild-type) strain, which, when incubated under the same conditions, does not display any diversification. The $m u t S$ variant, $\mathrm{mS2}$, is easily distinguished by its particular colony appearance: translucent and hyperpigmented, with a flat periphery spreading out around the colony. The mS2 variant notably shows several altered virulence traits (decreased elastase activity, increased pigment production and swarming motility, and decreased cytotoxicity to eukaryotic cells) and it is reproducibly originated from a distinct mutS variant precursor, $\mathrm{mS} 1$, which is phenotypically more similar to the wild-type strain (Smania et al., 2004). In the present study, we determined that the mS2 morphotypical diversification was based on distinct missense and nonsense point mutations in the lasR gene, while the gacA and $r h l R$ genes, positioned above and below in the QS regulatory cascade respectively, were not altered in the $\mathrm{mS} 2$ variants. We also determined that inactivation of LasR in the mS2 morphotype would confer selective advantages by increasing cell viability in the late stationary phase. It should be noted that the emergence of $P$. aeruginosa las $R$ mutants in vitro (Heurlier et al., 2005) as well as in clinical isolates including CF has been described previously (Hamood et al., 1996; Cabrol et al., 2003; Schaber et al., 2004; Dénervaud et al., 2004; Salunkhe et al., 2005). Thus, inactivation of LasR would constitute an important tool in adapting to particular environmental challenges, and the higher frequency of $\mathrm{mS} 2$ variants obtained from the mutator strain suggests a role for mutS hypermutability in acquiring these adaptive advantages.

\section{METHODS}

Bacterial strains, plasmids and media. The strains and plasmids used in this study are listed in Table 1 . The $\mathrm{mS} 1$ and $\mathrm{mS} 2$ variants were obtained from a stock of a P. aeruginosa Hex1T mutator mutS strain which was frozen immediately after the interruption of the mutS gene (Smania et al., 2004). For this purpose, the strain was incubated in LBS broth $\left(10 \mathrm{~g} \mathrm{NaCl} \mathrm{l}^{-1}, 10 \mathrm{~g}\right.$ soy-peptone $\mathrm{l}^{-1}$, and $5 \mathrm{~g}$ yeast extract $1^{-1}$ ) at $30^{\circ} \mathrm{C}$ for $200 \mathrm{~h}$ with constant aeration (220 r.p.m.). After that, $\mathrm{mS} 1$ (smooth and opaque) and mS2 (translucent and hyperpigmented) colonies were identified and several $\mathrm{mS} 1$ clones were isolated and frozen at $-70{ }^{\circ} \mathrm{C}$ in the presence of $15 \%(\mathrm{v} / \mathrm{v})$ glycerol. These frozen $\mathrm{mS} 1$ cells were the starting stocks used for the rest of the experiments. To prepare inocula, bacteria were routinely subcultured on LBS broth from the frozen stocks and cultured overnight at $30{ }^{\circ} \mathrm{C}$ shaken at 220 r.p.m. Other growth media used were skim milk agar for protease activity assays (Sokol et al., 1979), King's A medium for pigment quantification (King et al., 1954), and Yep and ABm for Agrobacterium tumefaciens $\mathrm{N}$-acylhomoserine lactone (AHL) detection assays (Chilton et al., 1974). Media used for Caenorhabditis elegans bacterial virulence assays were brain heart infusion (BHI) (Britania) and nematode growth (NG) medium (2.5 g soy-peptone $1^{-1}, 3 \mathrm{~g} \mathrm{NaCl} \mathrm{l} \mathrm{l}^{-1}, 5 \mathrm{mg}$ cholesterol $1^{-1}, 1 \mathrm{mM} \mathrm{MgSO} 4,25 \mathrm{mM}$ potassium phosphate, $\mathrm{pH}$ 6, $3.4 \%, w / v$, agar).

When required, antibiotics at the following concentrations were used: for $P$. aeruginosa $150 \mu \mathrm{g}$ gentamicin $\mathrm{ml}^{-1}, 60 \mu \mathrm{g}$ tetracycline $\mathrm{ml}^{-1}$; for A. tumefaciens $30 \mu \mathrm{g}$ gentamicin $\mathrm{ml}^{-1}$. Standard molecular biology protocols were used throughout as described by Sambrook et al. (1989). The C. elegans N2 strain was maintained under standard culture conditions on NG agar and fed with Escherichia coli OP50 cells.

\section{Phenotypic characterization assays}

(i) Elastase activity determination. Supernatants from $P$. aeruginosa stationary-phase LBS cultures were tested for elastolytic activity (LasB protease) by the elastin-Congo red hydrolysis assay as described by Aendekerk et al. (2002).

(ii) Exoprotease activity determination. $P$. aeruginosa secreted protease (AprA) was detected on plates containing milk medium agar (Sokol et al., 1979) consisting of peptone from casein $5 \mathrm{~g} \mathrm{l}^{-1}$ (Merck), skim milk $10 \mathrm{~g} \mathrm{l}^{-1}$, yeast extract $2.5 \mathrm{~g} \mathrm{l}^{-1}$, and $1 \%(\mathrm{w} / \mathrm{v})$ agar (Britania) supplemented with glucose $\left(1 \mathrm{~g} \mathrm{l}^{-1}\right)$. Cells were point-inoculated with a sterile toothpick. After $24 \mathrm{~h}$ incubation at $37^{\circ} \mathrm{C}$, the diameters of the clearing zones around the inocula were measured. 
Table 1. Strains, plasmids and primers

\begin{tabular}{|c|c|c|}
\hline Strain, plasmid or primers & Relevant genotype and phenotype ${ }^{\star}$ & Source or reference \\
\hline \multicolumn{3}{|l|}{ Bacterial strains } \\
\hline \multicolumn{3}{|l|}{ Pseudomonas aeruginosa } \\
\hline HexlT & Wild-type, isolated from hydrocarbon-contaminated soil & Pezza et al. (2002) \\
\hline $\mathrm{mS} 1$ & $\begin{array}{l}\text { mutS: : kan derivative of Hex1T; mutator strain, opaque colonies } \\
\text { equivalent to the parent strain following diversification experiment; } \mathrm{Km}^{\mathrm{r}}\end{array}$ & Smania et al. (2004) \\
\hline $\mathrm{mS2}$ & $\begin{array}{l}\text { mutS: : kan derivative of Hex } 1 \mathrm{~T} \text {; mutator strain, transparent colonies } \\
\text { emergent from } \mathrm{mS} 1 \text { following diversification experiment; } \mathrm{Km}^{\mathrm{r}}\end{array}$ & This study \\
\hline MPAO1 & Wild-type & Jacobs et al. (2003) \\
\hline MPAO1 gacA & gacA:: ISphoA-hah (ID 37742) derivative of MPAO1; $\mathrm{Tc}^{\mathrm{r}}$ & Jacobs et al. (2003) \\
\hline MPAO1 lasR & lasR:: ISlacZ-hah (ID 17281) derivative of MPAO1; $\mathrm{Tc}^{\mathrm{r}}$ & Jacobs et al. (2003) \\
\hline \multicolumn{3}{|l|}{ Agrobacterium tumefaciens } \\
\hline NT1 & Ti plasmid-cured derivative of strain C58; AHL non-producing strain & Watson et al. (1975) \\
\hline NTL4(pTiC58 & NT1 carrying pTiC58 $\Delta \mathrm{accR}$; AHL constitutive expressing strain & Shaw et al. (1997) \\
\hline NTL4(pZLR4) & $\begin{array}{l}\text { NT1 carrying pZLR4, which expresses traR from its native promoter and } \\
\text { carries a TraR-dependent traG:: lacZ reporter fusion; exogenous } \\
\text { long-chain AHL detecting strain; } \mathrm{Gm}^{\mathrm{r}}\end{array}$ & Luo et al. (2003) \\
\hline \multicolumn{3}{|l|}{ Chromobacterium violaceum } \\
\hline CV026 & $\begin{array}{l}\text { cviI:: Tn5 derivative of ATCC 31532; exogenous short-chain AHL } \\
\text { detecting strain; } \mathrm{Km}^{\mathrm{r}}\end{array}$ & McClean et al. (1997) \\
\hline \multicolumn{3}{|l|}{ Nematodes } \\
\hline Caenorhabditis elegans & Wild-type N2 strain & $\begin{array}{l}\text { Caenorhabditis Genetics } \\
\text { Center }\end{array}$ \\
\hline \multicolumn{3}{|l|}{ Plasmids } \\
\hline pME3827 & pME6001carrying a functional PAO1 lasR gene; $\mathrm{Gm}^{\mathrm{r}}$ & Pessi \& Hass $(2000)$ \\
\hline pME3853 & $\begin{array}{l}\text { pME6010 with a } 174 \text { bp lasI upstream fragment and translational } \\
\text { lasI:: lacZ fusion containing the first } 13 \text { lasI codons }\end{array}$ & Pessi et al. (2001) \\
\hline pME3846 & $\begin{array}{l}\text { pME6010 with a } 666 \mathrm{bp} \text { rhlI upstream fragment and a translational } \\
\text { rhlI:: lac } Z \text { fusion containing the first } 14 \text { rhlI codons }\end{array}$ & Pessi et al. (2001) \\
\hline Primers & Sequence & \\
\hline GA-for & 5'-TGCGCCAAGCTAGGTCATGGG-3' upstream gacA & \\
\hline GA-rev & 5'-CCACGTAGAGAAGCTTGGCCT-3' downstream gacA & \\
\hline LR-for & 5'-CACGGGCGCATGCGCCTC-3' upstream lasR & \\
\hline LR-rev & 5'-AAGCTTCTATATAGAAGGGCAA-3' downstream lasR & \\
\hline RR-for & 5'-GCCATGATTTTGCCGTATCGG-3' upstream $r h l R$ & \\
\hline RR-rev & $5^{\prime}$-CTAAAGGAGGATGAACGGCAG-3' downstream $r h l R$ & \\
\hline
\end{tabular}

${ }^{\star} \mathrm{Tc}^{\mathrm{r}}$, tetracycline resistance; $\mathrm{Gm}^{\mathrm{r}}$, gentamicin resistance; $\mathrm{Km}^{\mathrm{r}}$, kanamicin resistance.

(iii) Pyocyanin quantification. Pyocyanin was assayed by measuring the absorbance at $695 \mathrm{~nm}$ of cell-free supernatants after cell growth for $72 \mathrm{~h}$ at $30^{\circ} \mathrm{C}$ in King's A broth.

(iv) Swarming motility assay. Swarming motility was assessed on swarm plates containing 8 g Bacto-peptone $1^{-1}$ (BD), $0.5 \% \mathrm{w} / \mathrm{v}$ agar (Britania) supplemented with $5 \mathrm{~g}$ glucose $1^{-1}$. Cells were pointinoculated with a sterile toothpick. After incubation at $30^{\circ} \mathrm{C}$ for $72 \mathrm{~h}$, the diameter of the area covered by the swarm was measured.

(v) Nematode slow killing assay. The C. elegans slow killing assay was conducted as described by Tan et al. (1999a) with minor modifications. Briefly, $10 \mu \mathrm{l}$ aliquots of 1/10 dilutions of overnight bacterial cultures grown in King's B broth (King et al., 1954) were spread on NG medium in $5.5 \mathrm{~cm}$ Petri plates and incubated at $30^{\circ} \mathrm{C}$ for $24 \mathrm{~h}$. After incubation for $8-24 \mathrm{~h}$ at room temperature $\left(23-25^{\circ} \mathrm{C}\right)$, each plate was seeded with four L4-stage hermaphrodite wild-type
Bristol C. elegans strain N2 nematodes. Plates were incubated at $25^{\circ} \mathrm{C}$ and examined for live worms after 5 days. Worms were considered dead when they failed to respond to a touch. Worms that died as a result of getting stuck to the walls of the plate were excluded from the analysis. The non-virulent E. coli strain OP50 was used as a control. Each independent assay consisted of three or four replicates.

(vi) Nematode paralytic killing assay. All paralytic killing assays were carried out according to Gallagher \& Manoil (2001) with minor modifications. Briefly, $10 \mu \mathrm{l}$ aliquots of $1 / 10$ dilutions of BHI broth overnight cultures were spread onto $5.5 \mathrm{~cm}$ diameter $\mathrm{BHI}$ agar plates containing $12 \mathrm{ml} \mathrm{BHI}$ broth solidified with agar at $1.2 \%$ $(\mathrm{w} / \mathrm{v})$. After incubation for $24 \mathrm{~h}$ at $30^{\circ} \mathrm{C}$, C. elegans $\mathrm{N} 2$ nematodes from stock plates were collected in M9 buffer $\left(3 \mathrm{~g} \mathrm{KH}_{2} \mathrm{PO}_{4} \mathrm{l}^{-1}, 6 \mathrm{~g}\right.$ $\left.\mathrm{Na}_{2} \mathrm{HPO}_{4} \mathrm{l}^{-1}, 5 \mathrm{~g} \mathrm{NaCl} \mathrm{l}^{-1}, 1 \mathrm{mM} \mathrm{MgSO}_{4}\right)$, and a $50 \mu \mathrm{l}$ aliquot (containing approximately 40 adult worms) was spotted onto the $P$. 
aeruginosa lawn. The plates were then incubated for $4 \mathrm{~h}$ at room temperature with the lid on, and the number of live nematodes was scored. Worms were considered paralysed when they did not move spontaneously and did not respond to mechanical stimulation. E. coli strain OP50 was used as non-virulent control and each independent assay consisted of three replicates.

(vii) Detection of AHLs. To detect the autoinducer 3-oxo-C12-HSL, a Petri dish bioassay based on the use of the A. tumefaciens NTL4 strain was carried out as previously described (Cha et al., 1998). This reporter strain contained a traG: lac $Z$ reporter fusion in the plasmid pZLR4, which allowed the detection of a range of exogenous long-chain homoserine lactones including 3-oxo-C12-HSL. Briefly, the $P$. aeruginosa variants were point-inoculated with sterile toothpicks. Following $24 \mathrm{~h}$ incubation at $28^{\circ} \mathrm{C}$, the diameters of the diffusing blue zones around the inocula were measured. A. tumefaciens NTL4pTiC58 $\triangle a c c R$ and A. tumefaciens NT1 were used as positive and negative assay controls respectively. The results were expressed in relation to the $P$. aeruginosa HexlT parental strain, whose values were considered as the maximum.

To detect the autoinducer C4-HSL, a reporter plate bioassay that employed a Chromobacterium violaceum CV026 strain, whose endogenous AHL synthase gene ( $c v i I)$ was disrupted allowing the detection of exogenous short-chain AHLs such as C4-HSL, was performed as previously described (McClean et al., 1997). The analysis was carried out with $50 \mu \mathrm{l}$ culture supernatant obtained from each $P$. aeruginosa variant, grown overnight in $\mathrm{AB}$ minimal glucose medium (Chilton et al., 1974) at $30^{\circ} \mathrm{C}$ with aeration (220 r.p.m.).

LasR function reporter assay. $P$. aeruginosa $\mathrm{Hex} 1 \mathrm{~T}, \mathrm{mS} 1$ and $\mathrm{mS} 2-\mathrm{A}$ to $\mathrm{J}$ variants, previously transformed with pME3853 and pME3846 plasmids containing translational lasI::lacZ and rhlI:: lac Z fusions respectively (Table 1), were grown in LBS with aeration at $30^{\circ} \mathrm{C}$. $\beta$-Galactosidase measurements were performed by the Miller method (Sambrook et al., 1989).

PCR assays. To amplify the coding regions of the gacA, rhlR and lasR genes (PA2586, PA3477 and PA1430 respectively) specific primers (Table 1) were designed on the basis of the PAO1 genome sequence (http://www.pseudomonas.com). PCR was performed using genomic DNA from different $P$. aeruginosa $\mathrm{mS2}-\mathrm{A}$ to $\mathrm{J}$ variants as well as $\mathrm{mS1}$ and Hex1T wild-type strains as templates under the following conditions: $3 \mathrm{~min}$ at $95^{\circ} \mathrm{C}, 35$ cycles of $1 \mathrm{~min}$ at $94^{\circ} \mathrm{C}, 1 \mathrm{~min}$ at $50^{\circ} \mathrm{C}$ and $2 \mathrm{~min}$ at $72{ }^{\circ} \mathrm{C}$, and a final extension of $10 \mathrm{~min}$ at $72^{\circ} \mathrm{C}$.

Sequencing and molecular analysis of the coding regions of the gac, rhIR and lasR genes. The PCR products were cleaned with a Gel Purification kit (QIAGEN) and directly sequenced by using the respective PCR primers. To identify mutations in gacA, $r h l R$ and $l a s R$, the sequences obtained from the $\mathrm{mS} 2$ variants were compared with those obtained from the mS1variant and the Hex1T wild-type strain by BLAST analysis.

Genetic complementation analysis of mS2 variants. Complementation with the las ${ }^{+}$gene was performed using the plasmid pME3827 (Table 1). The plasmid was electroporated into $P$. aeruginosa $\mathrm{mS} 2-\mathrm{A}$ to $\mathrm{J}$ variants following standard procedures (Ausubel et al., 1992). Once electroporated, transformed clones were isolated and screened for alkaline protease activity and production of AHLs. P. aeruginosa MPAO1 lasR mutant (ID 17281) (Jacobs et al., 2003) complemented with pME3827 was used as a control.

\section{RESULTS}

\section{Phenotypic diversification upon $\boldsymbol{P}$. aeruginosa MMRS disruption}

In order to determine the factors that control $\mathrm{mS} 2$ emergence, we first performed a diversification experiment to confirm the reproducibility of this phenomenon and to obtain a frequency of $\mathrm{mS} 2$ emergence. For this purpose, 10 independent $P$. aeruginosa $\mathrm{mS} 1$ and 10 independent wildtypes clones were incubated in LBS broth $(10 \mathrm{ml}$ in $100 \mathrm{ml}$ flask) at $30^{\circ} \mathrm{C}$ with constant shaking (220 r.p.m.) for $200 \mathrm{~h}$. After that, appropriately diluted samples were plated on LBS agar $\left(1 \times 10^{3}\right.$ colonies per culture $)$ and $\mathrm{mS} 2$ variants were scored by visual inspection. We observed that $\mathrm{mS} 2$ reproducibly emerged from all $\mathrm{mS} 1$ cultures at an incidence of approximately $8-10 \%$, in contrast to the wild-type cultures, which maintained the same monomorphic colonies without any apparent morphological diversification (Fig. 1). In addition to their typical colony appearance, we determined that such $\mathrm{mS} 2$ variants had lower exoprotease activity than the wild-type strain (see below). These results confirmed that the $\mathrm{mS} 2$ variants were generated in a reproducible and consistent way. For further characterization, a total of $10 \mathrm{mS} 2$ variants (named mS2-A to J) were isolated from three independent diversified cultures (culture 1, mS2-A; culture 2, mS2-B and C; culture 3, mS2-D to J).

\section{Phenotypic characterization of $\mathbf{m S 2}$ variants}

Considering that the phenomenon of $\mathrm{mS} 2$ emergence produced simultaneous alterations in several virulence
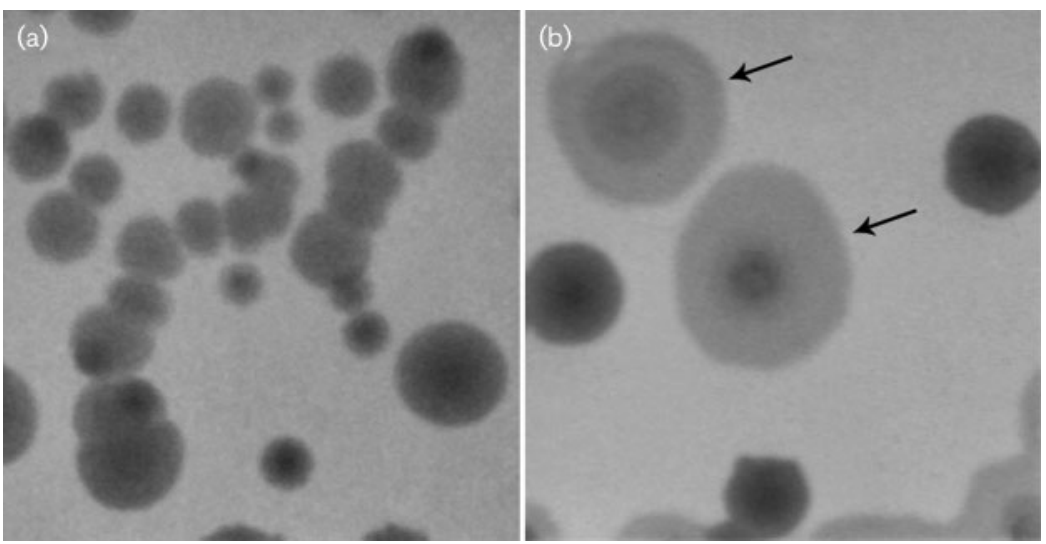

Fig. 1. Diversification in colony morphology of $P$. aeruginosa mutS strain. Equivalent inocula from single-colony overnight cultures were grown in $10 \mathrm{ml}$ nutrient LBS broth at $30{ }^{\circ} \mathrm{C}$ with shaking (220 r.p.m.) for $200 \mathrm{~h}$ and appropriate dilutions were plated on LBS agar and grown for $48 \mathrm{~h}$ at $30^{\circ} \mathrm{C}$. (a) $P$. aeruginosa Hex1T wild-type strain. (b) $P$. aeruginosa Hex1T mutS strain. Arrows indicate $\mathrm{mS} 2$ among $\mathrm{ms} 1$ variants. 
traits (Smania et al., 2004) we investigated the possibility that the $\mathrm{mS} 2$ diversification was the result of mutations in major QS regulators that simultaneously control the expression of such virulence determinants. With this aim, we carried out a detailed phenotypic characterization including measurement of pyocyanin and elastase production and swarming motility, analyses of specific markers for the detection of $P$. aeruginosa QS deficiency such as alkaline protease activity, AHL production, and two P. aeruginosaC. elegans killing assays, slow and paralytic killing.

The characterization was performed with the $10 \mathrm{mS} 2$ clones previously isolated (mS2-A to J) and, as controls, the wildtype $P$. aeruginosa HexlT strain, an $\mathrm{mS} 1$ clone, two engineered $P$. aeruginosa MPAO1 lasR and gacA mutants, and their MPAO1 parental strain (Jacobs et al., 2003). The choice of LasR and GacA as candidates was based on previous (Smania et al., 2004) and preliminary observations, mainly of avirulence and increased swarming motility, which suggested that $\mathrm{mS} 2$ phenotypic innovations may stem from mutations in the genes encoding any of these regulators. In addition, analysis of GacA was of interest due to previous reports that the incubation of distinct strains of Pseudomonas in rich liquid cultures at late stationary phase produced spontaneous and highly frequent gacA mutants (Duffy \& Defago, 2000; Bull et al., 2001).

As shown in Table 2, the mS2-A to J clones all displayed, in comparison to the parental Hex1T wild-type and mS1 strains: 4-12-fold more pyocyanin production; half the exoprotease activity; barely detectable elastolytic activity; approximately 1.5 -fold increased swarming motility; an avirulent phenotype in both $C$. elegans slow and paralytic assays; and scarcely detectable levels of C4-HSL and 3-oxoC12-HSL, with the sole exception of clone mS2-B, which produced equivalent levels of long-chain AHLs to the wildtype and $\mathrm{mS} 1$ strains.

The $P$. aeruginosa MPAO1 lasR mutant showed alterations similar to the $\mathrm{mS} 2$ clones, except that pyocyanin was not hyperproduced. The gacA mutant exhibited increased swarming motility, diminished production of pyocyanin,

Table 2. Phenotypic characterization of $P$. aeruginosa mS2 variants

\begin{tabular}{|c|c|c|c|c|c|c|c|c|}
\hline Strain & Pyocyanin ${ }^{\star}$ & Exoprotease $\dagger$ & Elastase $\ddagger$ & Swarming $§$ & $\begin{array}{c}\text { Slow- } \\
\text { killing } \\
\text { conditions|l }\end{array}$ & $\begin{array}{c}\text { Paralytic } \\
\text { conditions } 9\end{array}$ & $\begin{array}{l}\text { Long-chain } \\
\text { AHLs } \\
\text { production\# }\end{array}$ & $\begin{array}{l}\text { Short-chain } \\
\text { AHLs } \\
\text { production }^{\star *}\end{array}$ \\
\hline $\mathrm{mS2}-\mathrm{B}$ & $1.25 \pm 0.17$ & $1.10 \pm 0.28$ & $0.04 \pm 0.01$ & $1.60 \pm 0.02$ & - & - & ++ & - \\
\hline $\mathrm{mS} 2-\mathrm{C}$ & $1.16 \pm 0.13$ & $0.70 \pm 0.12$ & $0.04 \pm 0.01$ & $1.80 \pm 0.40$ & - & - & - & - \\
\hline $\mathrm{mS} 2-\mathrm{F}$ & $1.13 \pm 0.01$ & $0.96 \pm 0.08$ & $0.02 \pm 0.01$ & $2.00 \pm 0.28$ & - & - & - & - \\
\hline $\mathrm{mS} 2-\mathrm{G}$ & $1.07 \pm 0.01$ & $0.90 \pm 0.14$ & $0.04 \pm 0.01$ & $2.36 \pm 0.22$ & - & - & - & - \\
\hline $\mathrm{mS} 2-\mathrm{H}$ & $1.18 \pm 0.11$ & $0.90 \pm 0.16$ & $<0.01$ & $2.10 \pm 0.70$ & - & - & - & - \\
\hline mS2-I & $1.14 \pm 0.02$ & $1.06 \pm 0.22$ & $<0.01$ & $2.20 \pm 0.28$ & - & - & - & - \\
\hline $\mathrm{mS2}-\mathrm{J}$ & $1.07 \pm 0.07$ & $0.96 \pm 0.08$ & $0.03 \pm 0.02$ & $1.90 \pm 0.50$ & - & - & - & - \\
\hline MPAO1 & $0.08 \pm 0.01$ & $1.68 \pm 0.20$ & $0.16 \pm 0.04$ & ND & ++ & ++ & ++ & $\mathrm{ND}$ \\
\hline
\end{tabular}

ND, Not determined.

${ }^{*} A_{695}$ (mean of three replicate cultures).

$\dagger$ Diameter of the clearing zones around the bacterial spots in $\mathrm{cm}$ (mean of three replicates).

$\ddagger A_{495}$ (mean of three replicates).

$\S$ Diameter of motility area in $\mathrm{cm}$. Assayed on $0.5 \%$ agar plate as previously described.

IIRate of slow killing relative to wild-type HexlT strain: ++ , indistinguishable; + , moderately reduced; - , severely reduced (see Methods).

SRate of paralysis of worms relative to wild-type HexlT strain: ++ , indistinguishable; + , moderately reduced; - , severely reduced (see Methods).

\#Assessed by traG: lacZ reporter. Size of diffusing blue colour in the overlay surrounding the bacterial spot relative to wild-type Hex1T strain: ++ indistinguishable (wide); + , moderately reduced (narrow); - , severely reduced (not detectable) (see Methods). Assays were performed twice, in duplicate.

${ }^{*}$ Assessed by C. violaceum CV026 Petri dish assay. Size of purple haloes around the bacterial spot relative to wild-type Hex1T strain: ++ , indistinguishable (wide); +, moderately reduced (narrow); -, severely reduced (not detectable) (see Methods). Assays were performed twice, in duplicate. 
and severely reduced virulence in the C. elegans slow killing assay, which was in accordance with previous reports (Reimmann et al., 1997; Tan et al., 1999b). However, the levels of exoprotease and elastase activity and the behaviour in the C. elegans paralytic killing assays were equivalent to those obtained from the MPAO1, Hex1T and mS1 strains (Table 2). These data suggest that the pleiotropic phenotypes of the $\mathrm{mS} 2$ variants could be based on defective LasR function.

\section{The emergence of $\mathrm{mS2}$ variants is produced by spontaneous mutations in the las $R$ gene}

In order to determine the molecular bases of $P$. aeruginosa $\mathrm{mS} 2$ emergence, the gacA and lasR coding regions of mS2-A to $\mathrm{J}$ variants and of $\mathrm{mS} 1$ and Hex1T wild-type strains were isolated by PCR amplification and sequenced. In this analysis the sequencing of the rhlR coding region gene was also included, with the intention of analysing the complete QS cascade. As shown in Table 3, every $\mathrm{mS2}$ variant contained point mutations in the lasR coding region, whereas the gacA and $r h l R$ sequences showed no change with respect to the Hex1T wild-type and $\mathrm{mS} 1$ sequences in all ten $\mathrm{mS} 2$ variants analysed. All the mutations found in the las $R$ sequences of the mS2 clones were single missense and nonsense base substitutions, mainly transitions resulting in amino acid changes or the introduction of a premature stop codon (Table 3). Some clones contained point mutations that produced changes in the amino acids of the $\mathrm{N}$-terminal portion of LasR, which is known to be involved in binding with 3-oxo-C12-HSL and in protein multimerization (Kiratisin et al., 2002) (Fig. 2). Moreover, most mutations altered highly conserved amino acids present in the LuxRtype transcription factors (Vannini et al., 2002). Other clones contained point mutations generating substitutions in conserved amino acids of the C-terminal region (Table 3), which has been predicted to be the DNA binding domain of the protein (Kiratisin et al., 2002) (Fig. 2).

Table 3. Mutations in the las $R$ gene of $P$. aeruginosa $\mathrm{mS} 2$ variants

\begin{tabular}{|lll|}
\hline mS2 variants & las $\boldsymbol{R}$ mutation & Stop $^{*}$ or change $\dagger$ \\
\hline $\mathrm{mS} 2-\mathrm{A}$ & $\mathrm{G} \rightarrow \mathrm{A}$ at 236 & $\mathrm{C} 79 \mathrm{Y}$ \\
$\mathrm{mS} 2-\mathrm{B}$ & $\mathrm{C} \rightarrow \mathrm{T}$ at 665 & $\mathrm{~T} 222 \mathrm{I}$ \\
$\mathrm{mS} 2-\mathrm{C}$ & $\mathrm{C} \rightarrow \mathrm{T}$ at 692 & $\mathrm{~A} 231 \mathrm{~V}$ \\
$\mathrm{mS} 2-\mathrm{D}$ & $\mathrm{C} \rightarrow \mathrm{T}$ at 241 & $\mathrm{TAG}$ at 241 \\
$\mathrm{mS} 2-\mathrm{E}$ & $\mathrm{C} \rightarrow \mathrm{T}$ at 241 & $\mathrm{TAG}$ at 241 \\
$\mathrm{mS} 2-\mathrm{F}$ & $\mathrm{T} \rightarrow \mathrm{C}$ at 667 & $\mathrm{~S} 223 \mathrm{P}$ \\
$\mathrm{mS} 2-\mathrm{G}$ & $\mathrm{T} \rightarrow \mathrm{G}$ at 452 & $\mathrm{~L} 151 \mathrm{R}$ \\
$\mathrm{mS} 2-\mathrm{H}$ & $\mathrm{T} \rightarrow \mathrm{C}$ at 329 & $\mathrm{~L} 110 \mathrm{P}$ \\
$\mathrm{mS} 2-\mathrm{I}$ & $\mathrm{C} \rightarrow \mathrm{T}$ at 244 & $\mathrm{~T} 115 \mathrm{I}$ \\
$\mathrm{mS} 2-\mathrm{J}$ & $\mathrm{C} \rightarrow \mathrm{T}$ at 250 & $\mathrm{P} 117 \mathrm{~L}$ \\
\hline
\end{tabular}

${ }^{*}$ Termination codon generated at the site of the alteration.

$\dagger$ Changes relative to the lasR sequence gene of $P$. aeruginosa Hex1T wild-type strain.
It is important to note that two clones (mS2-D and E) had the same point mutation in codon $241(\mathrm{CAG} \rightarrow \mathrm{TAG})$, which would result in a truncated protein via the introduction of a premature stop codon (Table 3). These two clones were obtained from the same culture, suggesting that they were probably produced by the same mutation event. However, other clones (mS2-F, G, H, I and J) obtained from the same culture replica showed different kinds of sequence alterations, indicating that these variants had not arisen from mere selection of a single las $R$ mutation, but from independent mutational events. Equally, clones mS2-B and C, which arose from the same culture, showed distinct missense mutations, suggesting that mutational events in lasR have a notably high frequency.

Importantly, when plasmid pME3827, containing a functional lasR $R^{+}$gene from strain PAO1 (Pessi \& Haas, 2000), was introduced into every $\mathrm{mS} 2$ variant, the exoprotease activity, the production of 3-oxo-C12-HSL, and the opaque, smooth and convex colony morphology were restored to the phenotypes shown by HexlT wild-type and mS1, clearly indicating that the mutations found in the las $R$ gene constituted the cause of the diversification into mS2. Furthermore, to determine the effects of each amino acid substitution on LasR function, we examined, in each of the $\mathrm{mS} 2-\mathrm{A}$ to J clones, the LasR-dependent expression of the $P$. aeruginosa genes encoding the AHL synthases, lasI and rhlI. By using the plasmids pME3853 and pME3846, carrying translational lasI::lacZ and rhlI::lacZ reporter fusions respectively, we observed that in wild-type and $\mathrm{mS} 1$ backgrounds, expression of lasI and rhlI was similar, reaching a maximum at the stationary phase (not shown). However, all $\mathrm{mS} 2$ variants showed drastically reduced expression levels of lasI and rhlI even in late stationary phase $\left(\mathrm{OD}_{600} 3-5\right)$ (Fig. 3), indicating that independent of their nature and location, the lasR mutations would cause inactivation of LasR.

\section{Emergence kinetics of $\boldsymbol{P}$. aeruginosa $\mathrm{mS2}$ in batch culture}

Although the emergence of mS2 (lasR) mutants was clearly observed in the mutator $P$. aeruginosa Hex1T strain (Smania et al., 2004), we examined whether it also occurs in the wildtype non-mutator strain. To investigate this possibility, we carried out a new diversification experiment, growing three independent cultures of the $\mathrm{mS} 1$ variant and of the wildtype $P$. aeruginosa Hex1T strain under the same conditions as described above, but for longer periods $(300,400$ and $500 \mathrm{~h}$ ). Again, the emergence of mS2-like morphotypes was scored by visual inspection and confirmed by exoprotease activity determination and production of AHLs.

As shown in Fig. 4(a), after $100 \mathrm{~h}$ incubation mS2 represented $0.5 \%$ of the total cells in $\mathrm{mS} 1$ cultures, a percentage that exponentially increased with the incubation time, reaching almost $70 \%$ at $500 \mathrm{~h}$. In contrast, the wild-type cultures did not show any evidence of diversification until $400-500 \mathrm{~h}$ incubation, when a small proportion (4-5\%) of 


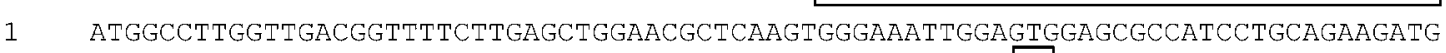

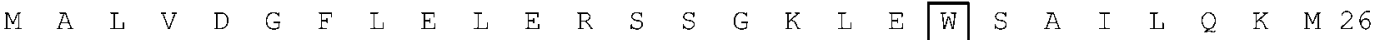

157 GTCGGCAACTACCCGGCCGCCTGGCGCGAGCATTACGACCGGGCTGGCTACGCGCGGGTCGACCCGACGGTCAGTCAC

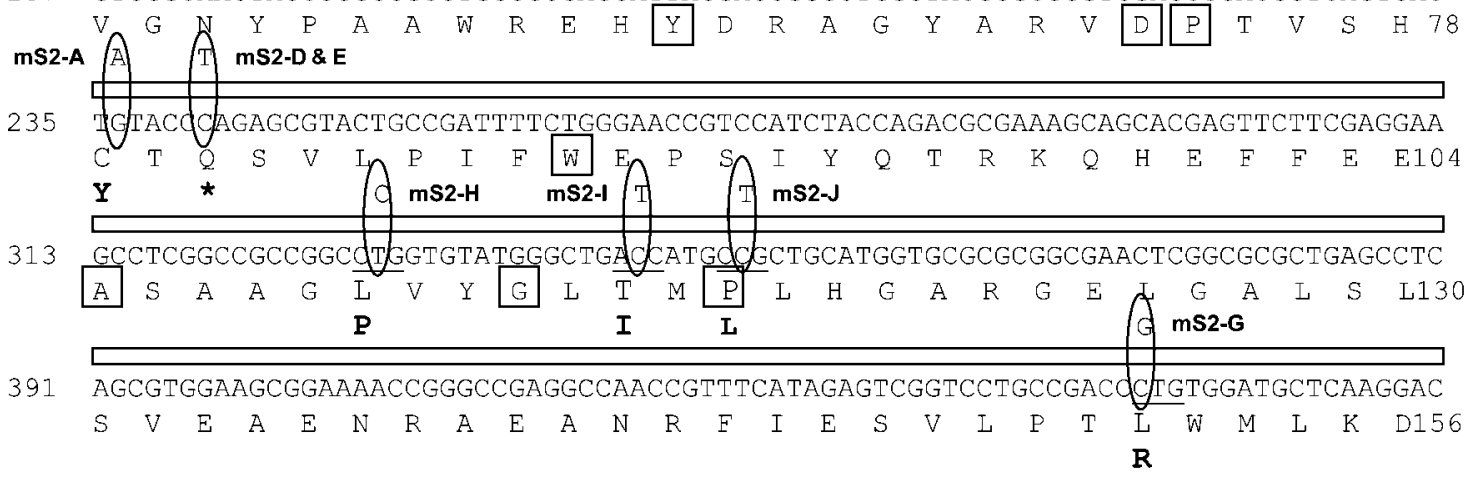

469 TACGCACTGCAGAGCGGTGCCGGACTGGCCTTCGAACATCCGGTCAGCAAACCGGTGGTTCTGACCAGCCGGGAGAAG $\begin{array}{llllllllllllllllllllllllllllll}Y & A & L & Q & S & G & A & G & L & A & F & E & H & P & V & S & K & P & V & V & L & T & S & R & E & K 182\end{array}$

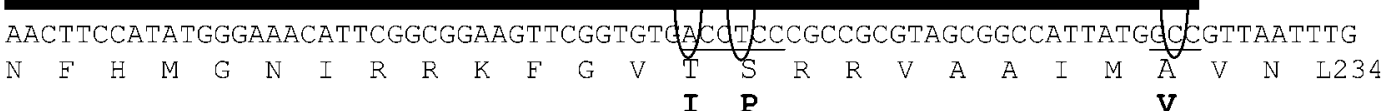

703 GGTCTTATTACTCTCTGA

G L I T L *

Fig. 2. Mutations in the las $R$ genes of $P$. aeruginosa $\mathrm{mS} 2$ variants. The nucleotide sequence alterations in $\mathrm{mS} 2-\mathrm{A}$ to $\mathrm{J}$ were identified by alignment with the $P$. aeruginosa Hex1T las $R$ sequence. Nucleotide substitutions that occurred in each mS2 variant are indicated by encircled nucleotides. Bold letters indicate the amino acid substitutions, and asterisks indicate stop codons. Underlined triplets indicate the codon affected. The autoinducer-binding and DNA-binding domains are indicated by white and black bars, respectively. Letters in boxes show the amino acids involved in LasR multimerization according to Kiratisin et al. (2002).

translucent and hyperpigmented flat bordered mS2-like colonies emerged (Fig. 4a). Interestingly, by quantifying the total c.f.u. of each $\mathrm{mS} 1$ culture, it was observed that, at 50-200 h, the number of mS1 cells decreased. In contrast, the emergent $\mathrm{mS} 2$ showed a clear increase in cell numbers until $200 \mathrm{~h}$ when it also started to decline but with a flatter slope than $\mathrm{mS} 1$ (Fig. 4a). This growth of $\mathrm{mS} 2$ could be explained as a consequence of generation and/or selection events. In this context, it is important to remember that most of the mS2 clones isolated at $200 \mathrm{~h}$ (mS2-A to J variants), contained different kinds of lasR mutations, thus indicating the relevance of mutational generation events over selection events in the $\mathrm{mS} 2$ enrichment process. In addition, since at $500 \mathrm{~h}$ the number of $\mathrm{mS} 2$ cells overtook $\mathrm{mS} 1$, it may be suggested that $\mathrm{mS} 2$ would have a selective advantage in the late stationary phase.
To investigate if the translucent wild-type variants were based on lasR mutations, five mS2-like wild-type clones with low exoprotease activity were selected for nucleotide sequencing of the lasR gene. Interestingly, one of them showed an unaltered lasR gene sequence; another displayed a point mutation in codon 676 resulting in a V226I substitution; and the other three contained the same point mutation in codon 55 (TGG $\rightarrow$ TGA), producing a LasR truncation by the introduction of a premature stop codon.

From these experiments, we concluded that the frequency of emergence of lasR mutants from the $\mathrm{mS} 1$ mutator variant was significantly higher than that of the wild-type. Also, it seems evident that the tested incubation conditions are mainly acting as a selector for las $R$ mutants in the mutator, since all the $\mathrm{mS} 2$ analysed variants were based on mutations 
(a)

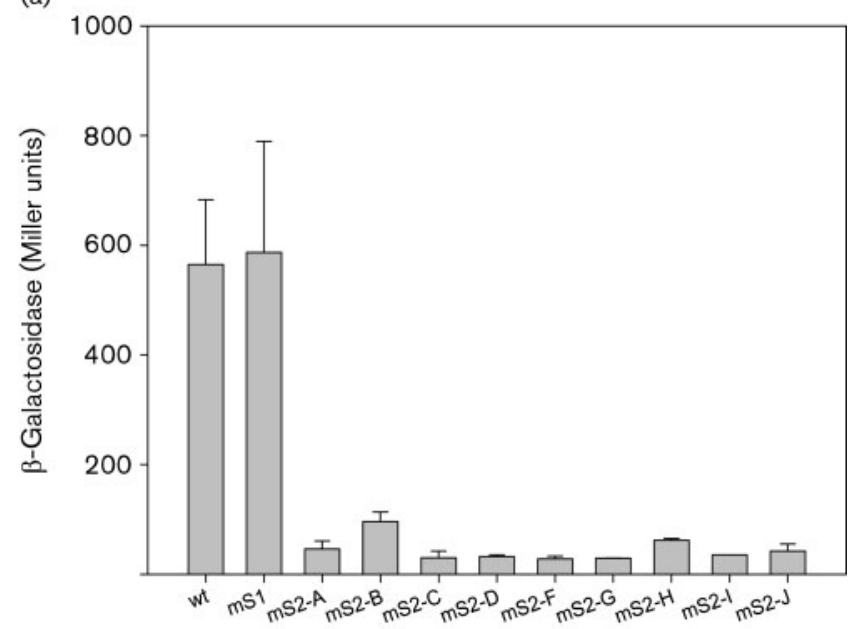

(b)

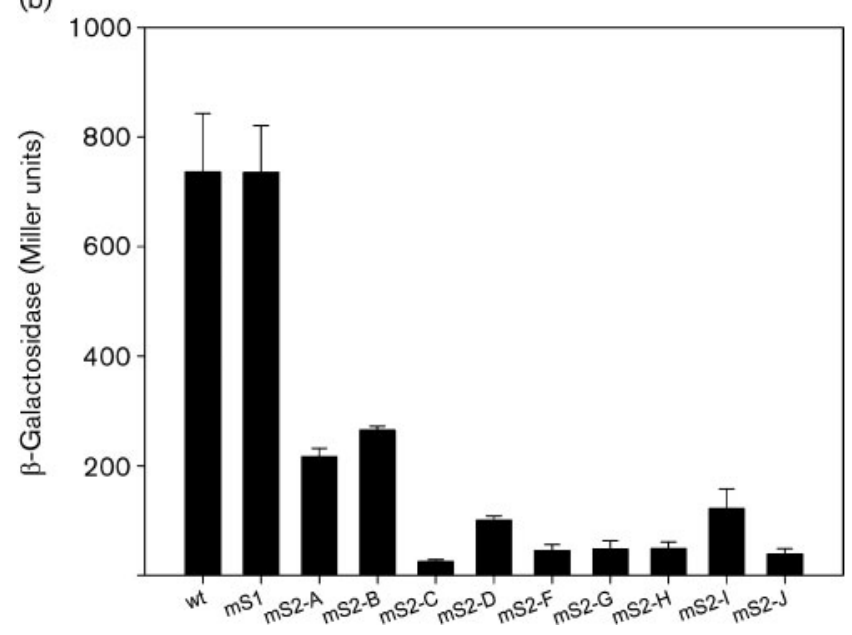

Fig. 3. Expression of the $\mathrm{AHL}$ synthases encoded by the las/ and rhll genes. $\beta$-Galactosidase activities resulting from the translational fusions las/: : lacZ carried by plasmid pME3853 (a) and $r h l l:$ : lacZ on plasmid pME3846 (b) were determined from stationary phase cultures of $P$. aeruginosa wild-type Hex1T, $\mathrm{mS} 1$ variant and $\mathrm{mS} 2$ variants $\mathrm{A}$ to $\mathrm{J}$ grown in LBS at $30^{\circ} \mathrm{C}$ with aeration (220 r.p.m.). Each value is the mean $\pm S D$ of three cultures. Data for ms2-E are not included because it contains the same missense mutation as ms2-D.

in the lasR gene. On the other hand, although lasR mutants seemed to predominate in mS2-like wild-type populations, they could also originate from mutations in other genes that are at present unknown.

\section{The inactivation of las $R$ increases viability of mS2 variants in late stationary phase}

Finally, to evaluate the behaviour of $\mathrm{mS} 2$ (lasR) mutants, we determined the cell viability under the same conditions as in the previous diversification experiments. Equivalent inocula from single-colony overnight cultures of Hex1T wild-type, $\mathrm{mS} 1, \mathrm{mS} 2-\mathrm{D}$ and MPAO1 lasR mutants were grown in
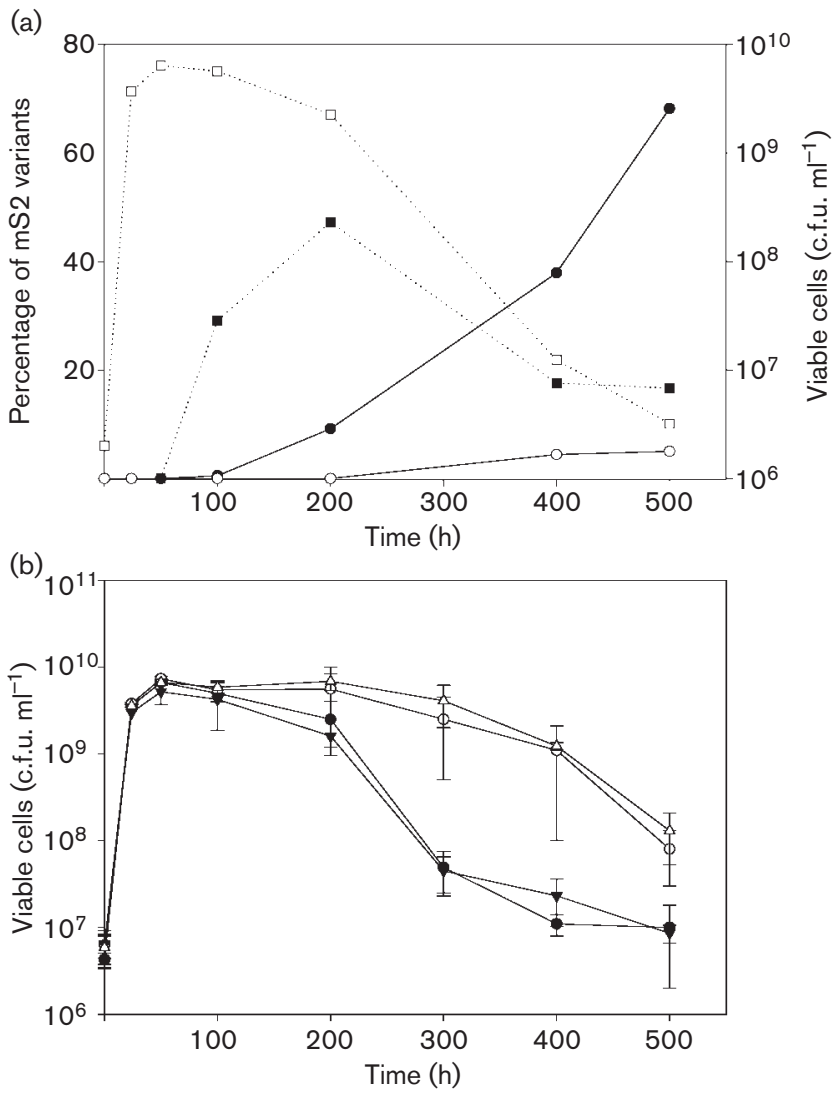

Fig. 4. Emergence of $\mathrm{mS} 2$ variants from $P$. aeruginosa $\mathrm{mS} 1$ and Hex1T strains. (a) Single-colony overnight cultures of $\mathrm{mS} 2$, $\mathrm{mS} 1$ and wild-type strains were inoculated in LBS broth and grown in triplicate in three independent cultures of $10 \mathrm{ml}$ LBS at $30{ }^{\circ} \mathrm{C}$ with shaking (220 r.p.m.) for 500 h. Appropriate dilutions of cultures were plated on LBS agar and mS2 colonies were distinguished by visual inspection (colonies with a flat transparent periphery) and decreased exoprotease activity. The percentages of $\mathrm{mS} 2$ with respect to the total number of colonies present in $\mathrm{mS} 1(\bullet)$ and in Hex1T $(\bigcirc)$ cultures are indicated. Total viable cells of $\mathrm{mS} 1(\square)$ and $\mathrm{mS} 2$ ( $\square$ ) are also indicated. (b) Growth of $P$. aeruginosa Hex1T, mS1, mS2-D and MPAO1 lasR. The strains were grown separately in $10 \mathrm{ml}$ LBS at $30^{\circ} \mathrm{C}$ with shaking (220 r.p.m.) for 500 h. Total viable cells were quantified by plating appropriate dilutions of the cultures of $\operatorname{Hex} 1 \mathrm{~T}(\boldsymbol{\nabla}), \mathrm{mS} 1(\bullet)$, and mS2-D $(\bigcirc)$, and MPAO1 las $R(\triangle)$ on LBS agar during the late stationary phase. Each point represents the mean of four parallel replicate cultures plated in duplicate.

triplicate in three independent cultures and appropriate dilutions were plated at different times on LBS agar in order to quantify the number of cells. As shown in Fig. 4(b), differences in numbers of c.f.u. were observed after 100-200 $\mathrm{h}$ incubation, when the $\mathrm{mS} 1$ and the wild-type showed a similar and notable decline in total cell numbers. Interestingly, the number of viable mS2-D variant was nearly constant until $200 \mathrm{~h}$ incubation, showing a gentle decrease over longer periods of time. Similar growth 
behaviour was observed in the MPAO1 lasR mutant strain (Fig. 4b). It is important to note that the time at which the difference in viability was evident among $\mathrm{mS} 2-\mathrm{D}, \mathrm{mS} 1$ and Hex1T wild-type strains (Fig. 4b) was coincident with the time at which $\mathrm{mS} 2$ began to emerge in the diversification culture (Fig. 4a). Another interesting observation was that after $200 \mathrm{~h}$ incubation, $\mathrm{mS} 1$ and wild-type cultures had a translucent appearance which was compatible with signals of cell lysis, whereas mS2-D and MPAO1 lasR maintained the characteristic dense appearance of saturated cultures. Recently, Heurlier et al. (2005) have shown the emergence of las $R$ mutants in cultures of $P$. aeruginosa PAO1 strain serially diluted in nutrient yeast broth. These authors determined that one of the potential causes of the emergence of lasR mutants is that they have a higher resistance to cell lysis produced by alkaline stress. In this context we determined that $\mathrm{mS2}, \mathrm{mS} 1$ and Hex1T wild-type cultures quickly reached a $\mathrm{pH}$ of up to 9 after $24 \mathrm{~h}$ incubation.

\section{DISCUSSION}

The potential role of mutators in evolution has been an issue of major biological and medical interest. Since they would have the capacity to generate adaptive mutations more quickly than the wild-type population, it has been postulated that, particularly in changing and stressful environments, mutator cells hasten the evolution of bacterial populations. Most of the mutator bacteria isolated in nature have been shown to be defective in the MMRS (LeClerc et al., 1996; Matic et al., 1997; Oliver et al., 2002), whose deficiency generates not only a mutator but also a hyperecombinogenic phenotype (Kunkel \& Erie, 2005). Thus, MMRS-deficient cells constitute a source of genetic diversity; and as a consequence they would be selected and maintained in a bacterial population.

In a previous article, we noted that, upon inactivation of $P$. aeruginosa Hex1T MMRS by disruption of the mutS gene and incubation in rich aerated media, a spontaneous and reproducible morphotypical diversification is produced, in contrast to the non-mutator wild-type strain that, incubated under the same conditions, does not manifest any kind of diversification (Smania et al., 2004). Based on these previous observations, we were particularly interested in the translucent and hyperpigmented $\mathrm{mS} 2$ morphotypical variant (Fig. 1), which reproducibly emerges from the smooth and opaque variant mS1 (Fig. 1) and displays differences in several phenotypic traits related to virulence and QS. In the present work, we isolated $10 \mathrm{mS} 2$ variants from independent diversification experiments and performed a detailed phenotypic characterization and gene sequence analyses, which revealed that spontaneous mutations in lasR were responsible for the $\mathrm{mS} 2$ phenotype. In fact, all $\mathrm{mS} 2$ variants analysed showed increased pyocyanin production and swarming motility, diminished exoprotease and elastolytic activity, scarcely detectable production of AHLs, and a substantially reduced virulence in a $P$. aeruginosa-C. elegans pathogenesis model (Table 2). Examining the lasR gene by
PCR and sequencing, we observed that all lasR sequences of the $\mathrm{mS} 2$ variants harboured simple but different base substitutions, as compared to the unaltered Hex1T wildtype and $\mathrm{mS} 1$ las $R$ sequences. Moreover, since the expression of the AHL synthase genes lasI and rhlI was reduced in all $\mathrm{mS} 2$ variants (Fig. 3) and the introduction of plasmid pME3827 containing a las $R^{+}$allele restored an mS1-like phenotype, we conclude that such mutations, although different in nature and location, severely affect LasR function and constitute the basis for the change from $\mathrm{mS} 1$ to $\mathrm{mS2}$.

Importantly, most lasR mutations found in $\mathrm{mS} 2$ variants consisted of transitions ( $90 \%$ ), mainly $\mathrm{C}$ to $\mathrm{T}$ substitutions (Table 3 ). This observation is in accordance with previous reports on E. coli MMRS-deficient cells, which demonstrated that the spectrum of base substitutions was dominated by $\mathrm{C}$ to $\mathrm{T}$ changes (Schaaper \& Dunn, 1987; Levy \& Cebula, 2001). Actually, all the point mutations observed in our analysis originated from mismatches that are normally recognized by a functional MutS (Modrich \& Lahue, 1996), indicating that an inefficient repair of such replication-related mismatches in the mutS mutant would explain the higher level of emergence of las $R$ mutants with respect to the non-mutator wild-type (Fig. 4).

It has been determined that the LasR $\mathrm{N}$-terminal region is involved in the binding of 3-oxo-C12-HSL and protein multimerization, whereas the C-terminal region has been predicted to be the DNA-binding domain (Kiratisin et al., 2002). Furthermore, by analysing single substitutions of conserved amino acids of LasR, Kiratisin et al. (2002) have observed that P117F severely affects the LasR multimerization and function whereas C79S and L110I have no effect on the ability of LasR to multimerize or function. Interestingly, we observed that the amino acids C79, L110 and P117 were substituted in the mS2-A, $\mathrm{H}$ and $\mathrm{J}$ clones respectively (Table 3). The substitution of P117L in clone mS2-J would have an equivalent effect to the P117F mutation reported previously. However, contrary to Kiratisin's observations, the spontaneous substitutions C79Y and L110P (mS2-A and $\mathrm{H}$ clones) altered LasR function (Table 2, Fig. 3). This discrepancy is not surprising since the amino acids involved in the substitutions carried out in Kiratisin's work (cysteine by serine and leucine by isoleucine) are structurally very similar whereas tyrosine, a large aromatic residue, and proline, a residue with highly restricted conformations, would generate substitutions that more drastically affect the protein structure. Thus, our results indicate that not only which residue is affected but also the nature of the substituted amino acid is important for LasR function. Furthermore, it seems that most of the LasR amino acid sequence is important for protein function since different kinds of simple amino acid substitutions throughout the protein affect its activity, suggesting that they have essential roles either in DNA and autoinducer binding or multimerization capacity (Figs 2 and 3 ). 
Considering clone mS2-B, we observed that a single point mutation at lasR codon 665 (ACC $\rightarrow$ ATC) produced the substitution T222I (Table 3). As mentioned, unlike the other $\mathrm{mS} 2$ clones, the level of long-chain AHLs for mS2-B was equivalent to that of the wild-type and $\mathrm{mS} 1$ strains (Table 2). Nevertheless, as in the rest of the mS2 variants, the expression of both lasI and rhlI AHL synthases was reduced in mS2-B (Fig. 3) and the exoprotease activity and the opaque and smooth colony aspects were restored by complementation with a functional las $R^{+}$gene. Additionally, it had no sequence alterations in gacA or in $r h l R$. One possible explanation could be a change in the promoter region of lasI that would allow the expression of the lactone synthase in spite of the fact that LasR activity was affected. Nevertheless, it would be based on a second suppressor mutation whose origin and nature remains to be elucidated.

The fact that lasR-negative mutants emerged as a consequence of several different point mutations indicates that the selection pressure acts on the las $R$ loss of function rather than on a particular mutational hot spot within the gene. Growth experiments showed that, under the conditions examined, the viability of lasR-defective mutants was increased, indicating that there would be a direct environmental selection in favour of them (Fig. 4). It is important to note that none of the $\mathrm{mS} 2$ variants analysed here contained any sequence alteration in the gacA and $r h l R$ genes, suggesting that, in such an environment, the selective pressures for GacA/RhlR and LasR were different. We found this observation interesting since other Pseudomonas species show a high instability in gacS-gacA genes in similar nutrient-rich liquid stationary phase cultures (Duffy \& Defago, 2000; Bull et al., 2001) and some QS-negative P. aeruginos a clinical isolates were affected in both the las $R$ and rhlR systems (Schaber et al., 2004; Dénervaud et al., 2004).

The extent of QS-regulated genes of P. aeruginosa is still not completely known and may involve much complex crossregulation between las and rhl systems, as well as other global regulators, thus exceeding the mere control of virulence. In this context, there is increasing evidence suggesting that the QS system could regulate a number of central metabolic functions such as glucose and adenosine catabolism (Schuster et al., 2003; Heurlier et al., 2005; Heurlier et al., 2006) and denitrification (Wagner et al., 2003). Recently, Heurlier et al. (2005) have proposed that alkaline lysis and death, induced by an increase in $\mathrm{pH}$ when $P$. aeruginosa grows in nutrient rich broth, may be the critical factor providing a selective survival advantage for lasR mutants. We also observed the alkalinization of the media after $24 \mathrm{~h}$ growth and a lower level of cell lysis for the $\mathrm{mS2}$ (lasR) variants compared to $P$. aeruginosa Hex1T and $\mathrm{mS1}$. In this context, it is important to mention the observations obtained by Yates and collaborators (2002) which indicate that the concomitant increase in the $\mathrm{pH}$ of the LB medium during the growth of $P$. aeruginosa to the stationary phase generates the spontaneous and reversible nonenzymic $\mathrm{pH}$-dependent hydrolysis of the AHL ring lactone. Thus, it is highly suggestive that media alkalinization not only would induce/select for lasR-deficient clones but also would 'turn off the secreted AHLs, both as confluent phenomena leading to QS defectiveness.

It has been previously reported that under casein starvation conditions, $P$. aeruginosa can mutate and restore elastase and rhamnolipid production despite a non-functional las system (van Delden et al., 1998). Such restoration requires an intact $r h l$ system, since it is produced by a suppressor mutation that affects the transcription of the rhlI synthase gene (van Delden et al., 1998). On the other hand, recent transcriptome analyses have allowed further insights into the particular role of each QS system, interestingly indicating that most of the $P$. aeruginosa QS-controlled virulence genes are primarily controlled by the RhlR-C4HSL system (Schuster et al., 2003; Schuster \& Greenberg, 2006). Therefore there would be an intriguing QS redundancy, with overlapping regulation between the las and $r h l$ systems as well as other global regulators that, acting in combination with the specific roles of each QS system, may constitute one of the bases of the exceptional plasticity of $P$. aeruginosa in responding to diverse environmental conditions. This trend and the high las system instability described here and by others (Heurlier et al., 2005; Salunkhe et al., 2005; Schaber et al., 2004; Cabrol et al., 2003; Hamood et al., 1996), should be taken into account in the light of new therapies designed to specifically block the las QS (Smith \& Iglewski, 2003b). In addition, it is important to consider that if QS plasticity based on mutational mechanisms, such as the acquisition of suppressor mutations (van Delden et al., 1998), exists, a mutator phenotype would also be crucial to accelerate the generation of such suppressor mutants. However, we consider that, even in a mutator background, an ever-existing fine tuning between generation and selection forces would be present to ensure the emergence of adaptive variants avoiding the accumulation of nonbeneficial or lethal mutations. In this context, it is important to mention that besides the observed $\mathrm{mS} 2$ diversification, which should be attributed to mutational events, the analysis of chromosomal DNA by pulsed-field gel electrophoresis revealed no obvious genetic rearrangements (unpublished data). This, together with transcriptome analyses of an E. coli mutS strain that shows that it does not display major differences from the wild-type at the transcriptional level (Robbins-Manke et al., 2005), would be important to mitigate concern about the possible influence of additional mutations generated in a mutS background.

As mentioned above, accumulation of mutations in las $R$ after in vitro incubation in aerated rich liquid media has been reported previously for $P$. aeruginosa PAO1 (Heurlier et al., 2005). Also, defects in the lasR gene have been detected in several clinical and environmental $P$. aeruginosa strains (Hamood et al., 1996; Cabrol et al., 2003; Schaber et al., 2004; Dénervaud et al., 2004). Furthermore, a recent report has described the isolation of lasR-defective mutants of the 
virulent and highly transmissible $P$. aeruginosa Liverpool epidemic strains obtained from CF patients (Salunkhe et al., 2005). These observations suggest that, in certain circumstances, the inactivation of the LasR-dependent regulatory system would be advantageous and would play an important role in $P$. aeruginosa pathogenesis. Our results additionally include a novel observation, that the acquisition of selective advantages through inactivation of LasR is greatly increased in $m u t S$-deficient strains. Several other studies have supported the postulate that the acquisition of stable mutator phenotypes may confer selective advantages for bacteria mainly in stressful and fluctuating environments such as the infection and establishment processes of a pathogen (LeClerc et al., 1996; Taddei et al., 1997; Giraud et al., 2001). Particularly in $P$. aeruginosa, almost $20 \%$ of the isolates obtained from chronically infected CF patients are stable mutators which are mainly produced by alteration of the mutS gene (Oliver et al., 2000, 2002). Interestingly, the development of antibiotic resistance has been clearly established as a CF chronic infection phenotype that, driven by hypermutation, constitutes the main force contributing to fixation of mutators (Oliver et al., 2000; Chopra et al., 2003; Maciá et al., 2005). Strikingly, by performing an analysis of mS2 grown in biofilms, we obtained a new spectrum of morphotypes, such as mucoid and small colony variants (unpublished data). This illustrates the increased versatility of $P$. aeruginosa MMRS-deficient cells and suggests that mutant phenotypes other than antibiotic resistance could act, probably by second-order selection processes, as alternative forces fixing mutator alleles in natural populations such as the CF lung. In this context, the findings reported here show the relevance of hypermutability via mutS deficiency favouring the acquisition of adaptive advantages through inactivation of LasR and provide interesting insights about the linkage between MMRS deficiency and the regulation of the QS system, a fundamental issue in $P$. aeruginosa adaptive processes.

\section{ACKNOWLEDGEMENTS}

We are grateful to Dr Michael Jacobs for providing the $P$. aeruginosa MPAO1 strain and its two gacA and lasR isogenic mutants, to Dr Dieter Haas for providing plasmid pME3827, to Dr Stephan Heeb for providing plasmids pME3853 and pME3846, and to the Caenorhabditis Genetics Center for providing the Bristol Caenorhabditis elegans strain N2. This work was supported by grants from the Consejo Nacional de Investigaciones Científicas y Técnicas (CONICET), the Agencia Nacional de Promoción de Ciencia y Técnica (ANPCYT), and the Secretaría de Ciencia y Técnica (SECYT-UNC).

\section{REFERENCES}

Aendekerk, S., Ghysels, B., Cornelis, P. \& Baysse, C. (2002). Characterization of a new efflux pump, MexGHI-OpmD, from Pseudomonas aeruginosa that confers resistance to vanadium. Microbiology 148, 2371-2381.

Ausubel, F., Brent, R., Kingston, R., Moore, D., Seidman, J., Smith, J. \& Struhl, K. (editors) (1992). Short Protocols in Molecular Biology, 2nd edn. New York: Greene Publishing Associates.
Bull, C. T., Duffy, B., Voisard, C., Defago, G., Keel, C. \& Haas, D. (2001). Characterization of spontaneous gacS and gacA regulatory mutants of Pseudomonas fluorescens biocontrol strain CHAO. Antonie Van Leeuwenhoek 79, 327-336.

Cabrol, S., Olliver, A., Pier, G. B., Andremont, A. \& Ruimy, R. (2003). Transcription of quorum-sensing system genes in clinical and environmental isolates of Pseudomonas aeruginosa. J Bacteriol 185, 7222-7230.

Cha, C., Gao, P., Chen, Y. C., Shaw, P. D. \& Farrand, S. K. (1998). Production of acyl-homoserine lactone quorum-sensing signals by gram-negative plant-associated bacteria. Mol Plant Microbe Interact 11, 1119-1129.

Chilton, M. D., Currier, T. C., Farrand, S. K., Benedecht, A. J., Gordont, M. P. \& Nester, E. W. (1974). Agrobacterium tumefaciens DNA and PS8 bacteriophage DNA not detected in crown gall tumors. Proc Natl Acad Sci U S A 71, 3672-3676.

Chopra, I., O'Neill, A. J. \& Miller, K. (2003). The role of mutators in the emergence of antibiotic-resistant bacteria. Drug Resist Updat 6, $137-145$.

Denamour, E. \& Matic, I. (2006). Evolution of mutation rates in bacteria. Mol Microbiol 60, 820-827.

Dénervaud, V., TuQuoc, P., Blanc, D., Reimmann, C., Haas, D. \& van Delden, C. (2004). Characterization of cell-to-cell signalling deficient Pseudomonas strains colonizing intubated patients. J Clin Microbiol 42, 554-562.

Duffy, B. K. \& Defago, G. (2000). Controlling instability in gacS-gacA regulatory genes during inoculant production of Pseudomonas fluorecens biocontrol strains. Appl Environ Microbiol 66, 3142-3150.

Gallagher, L. A. \& Manoil, C. (2001). Pseudomonas aeruginosa PAO1 kills Caenorhabditis elegans by cyanide poisoning. J Bacteriol 183, 6207-6214.

Giraud, A., Matic, I., Tenaillon, O., Clara, A., Radman, M., Fons, M. \& Taddei, F. (2001). Cost and benefits of high mutation rates: adaptive evolution of bacteria in the mouse gut. Science 291, 2606-2608.

Hamood, A. D., Griswold, J. \& Colmer, J. (1996). Characterization of elastase-deficient clinical isolates of Pseudomonas aeruginosa. Infect Immun 64, 3154-3160.

Heeb, S. \& Haas, D. (2001). Regulatory roles of the GacA/GacS twocomponent system in plant-associated and other Gram-negative bacteria. Mol Plant Microbe Interact 14, 1351-1363.

Heurlier, K., Denervaud, V., Haenni, M., Guy, L., Krishnapillai, V. \& Haas, D. (2005). Quorum-sensing-negative (lasR) mutants of Pseudomonas aeruginosa avoid cell lysis and death. J Bacteriol 187, 4875-4883.

Heurlier, K., Denervaud, V. \& Haas, D. (2006). Impact on quorum sensing on fitness of Pseudomonas aeruginosa. Int J Med Microbiol 296, 93-102.

Jacobs, M. A., Alwood, A., Thaipisuttikul, I., Spencer, D., Haugen, E., Ernst, S., Will, O., Kaul, R., Raymond C. \& other authors (2003). Comprehensive transposon mutant library of Pseudomonas aeruginosa. Proc Natl Acad Sci U S A 100, 14339-14344.

King, E. O., Ward, M. K. \& Raney, D. E. (1954). Two simple media for the demonstration of pyocyanin and fluorescein. J Lab Clin Med 44, 301.

Kiratisin, P., Tucker, K. D. \& Passador, L. (2002). LasR, a transcriptional activator of Pseudomonas aeruginosa virulence genes, functions as a multimer. J Bacteriol 184, 4912-4919.

Kunkel, T. A. \& Erie, D. A. (2005). DNA mismatch repair. Annu Rev Biochem 74, 681-710.

LeClerc, J. E., Baouguang, L., Payne, W. L. \& Cebula, T. A. (1996). High mutation frequencies among Escherichia coli and Salmonella pathogens. Science 274, 1208-1211. 
Levy, D. D. \& Cebula, T. A. (2001). Fidelity of replication of repetitive DNA in mutS and repair proficient Escherichia coli. Mutat Res 474, $1-14$.

Luo, Z. Q., Su, S. \& Farrand, S. K. (2003). In situ activation of the quorum-sensing transcription factor TraR by cognate and noncognate acyl-homoserine lactone ligands: kinetics and consequences. J Bacteriol 185, 5665-5672.

Lyczak, J. B., Cannon, C. L. \& Pier, G. B. (2002). Lung infections associated with cystic fibrosis. Clin Microbiol Rev 15, 194-222.

Maciá, M. D., Blanquer, D., Togores, B., Sauleda, J., Pérez, J. L. \& Oliver, A. (2005). Hypermutation is a key factor in development of multiple antimicrobial resistance in Pseudomonas aeruginosa strains causing chronic lung infections. Antimicrob Agents Chemother 49, 3382-3386.

Martin, C., Ichou, M. A., Massicot, P., Goudeau, A. \& Quentin, R. (1995). Genetic diversity of Pseudomonas aeruginosa strains isolated from patients with cystic fibrosis revealed by restriction fragment length polymorphism of the rRNA gene region. J Clin Microbiol 33, 1461-1466.

Matic, I., Radman, M., Taddei, F., Picard, B., Doit, C., Bingen, E., Denamur, E. \& Elion, J. (1997). Highly variable mutation rates in commensal and pathogenic Escherichia coli. Science 277, 1833-1834.

McClean, K. H., Winson, M. K., Fish, L., Taylor, A., Chhabra, S. R., Camara, M., Daykin, M., Lamb, J. H., Swift, S. \& other authors (1997). Quorum sensing and Chromobacterium violaceum: exploitation of violacein production and inhibition for the detection of $\mathrm{N}$-acylhomoserine lactones. Microbiology 143, 3703-3711.

McKnight, K. H., Iglewski, B. H. \& Pesci, E. C. (2000). The Pseudomonas quinolone signal regulates $\mathrm{rhl}$ quorum sensing in Pseudomonas aeruginosa. J Bacteriol 182, 2702-2708.

Modrich, P. \& Lahue, R. (1996). Mismatch repair in replication fidelity, genetic recombination, and cancer biology. Annu Rev Biochem 65, 101-133.

Oliver, A., Canton, R., Campo, P., Baquero, F. \& Blazquez, J. (2000). High frequency of hypermutable Pseudomonas aeruginosa in cystic fibrosis lung infection. Science 288, 1251-1254.

Oliver, A., Baquero, F. \& Blázquez, J. (2002). The mismatch repair system (mutS, mutL and uvrD genes) in Pseudomonas aeruginosa: molecular characterization of naturally occurring mutants. Mol Microbiol 43, 1641-1650.

Parkins, M. D., Ceri, H. \& Storey, D. G. (2001). Pseudomonas aeruginosa GacA, a factor in multihost virulence, is also essential for biofilm formation. Mol Microbiol 40, 1215-1227.

Pesci, E. C., Pearson, J. P., Seed, P. C. \& Iglewski, B. H. (1997). Regulation of las and rhl quorum sensing in Pseudomonas aeruginosa. J Bacteriol 179, 3127-3132.

Pesci, E. C., Milbank, J. B., Pearson, J. P., McKnight, S., Kende, A. S., Greenberg, E. P. \& Iglewski, B. H. (1999). Quinolone signalling in the cell-to-cell communication system of Pseudomonas aeruginosa. Proc Natl Acad Sci U S A 96, 11229-11234.

Pessi, G. \& Haas, D. (2000). Transcriptional control of the hydrogen cyanide biosynthetic genes $h c n A B C$ by the anaerobic regulator ANR and the quorum-sensing regulators LasR and RhlR in Pseudomonas aeruginosa. J Bacteriol 182, 6940-6949.

Pessi, G., Williams, F., Hindle, Z., Heurlier, K., Holden, M. T., Camara, M., Haas, D. \& Williams, P. (2001). The global posttranscriptional regulator RsmA modulates production of virulence determinants and $\mathrm{N}$-acylhomoserine lactones in Pseudomonas aeruginosa. J Bacteriol 183, 6676-6683.

Pezza, R. J., Smania, A. M., Barra, J. L. \& Argaraña, C. E. (2002). Nucleotides and heteroduplex DNA preserve the active conformation of Pseudomonas aeruginosa MutS by preventing protein oligomerization. Biochem J 361, 87-95.

Reimmann, C., Beyeler, M., Latifi, A., Winteler, H., Foglino, M., Lazdunski, A. \& Haas, D. (1997). The global activator GacA of Pseudomonas aeruginosa PAO1 positively controls the production of the autoinducer N-butyryl-homoserine lactone and the formation of the virulence factors pyocyanin, cyanide, and lipase. Mol Microbiol 24, 309-319.

Robbins-Manke, J. L., Zdraveski, Z. Z., Marinus, M. \& Essigmann, J. M. (2005). Analysis of global gene expression and doublestrand-break formation in DNA adenine methyltransferase- and mismatch repair-deficient Escherichia coli. J Bacteriol 187, 7027-7037.

Salunkhe, P., Smart, C. H., Morgan, J. A., Panagea, S., Walshaw, M. J., Hart, C. A., Geffers, R., Tümmler, B. \& Winstanley, C. (2005). A cystic fibrosis epidemic strain of Pseudomonas aeruginosa displays enhanced virulence and antimicrobial resistance. J Bacteriol 187, 4908-4920.

Sambrook, J., Fritsch, E. F. \& Maniatis, T. (1989). Molecular Cloning: a Laboratory Manual, 2nd edn. Cold Spring Harbor, NY: Cold Spring Harbor Laboratory.

Schaaper, R. M. \& Dunn, R. L. (1987). Spectra of spontaneous mutations in Escherichia coli strains defective in mismatch correction: the nature of in vivo DNA replication errors. Proc Natl Acad Sci U S A 84, 6220-6224.

Schaber, J. A., Carty, N. L., McDonald, N. A., Graham, E. D., Cheluvappa, R., Griswold, J. A. \& Hamood, A. N. (2004). Analysis of quorum sensing-deficient clinical isolates of Pseudomonas aeruginosa. J Med Microbiol 53, 841-853.

Schuster, M. \& Greenberg, E. P. (2006). A network of networks: quorum-sensing gene regulation in Pseudomonas aeruginosa. Int J Med Microbiol 296, 73-81.

Schuster, M., Lostroh, C. P., Ogi, T. \& Greenberg, E. P. (2003). Identification, timing, and signal specificity of Pseudomonas aeruginosa quorum-controlled genes: a transcriptome analysis. J Bacteriol 185, 2066-2079.

Shaw, P. D., Ping, G., Daly, S. L., Cha, C., Cronan, J. E., Rinehart, K. L. \& Farrand, S. K. (1997). Detecting and characterizing $\mathrm{N}$-acylhomoserine lactone signal molecules by thin-layer chromatography. Proc Natl Acad Sci U S A 94, 6036-6041.

Smania, A. M., Segura, I., Pezza, R. J., Becerra, C., Albesa, I. \& Argaraña, C. E. (2004). Emergence of phenotypic variants upon mismatch repair disruption in Pseudomonas aeruginosa. Microbiology 150, 1327-1338.

Smith, R. S. \& Iglewski, B. H. (2003a). Pseudomonas aeruginosa quorum sensing systems and virulence. Curr Opin Microbiol 6, $56-60$.

Smith, R. S. \& Iglewski, B. H. (2003b). Pseudomonas aeruginosa quorum sensing as a potential antimicrobial target. J Clin Invest 112, 1460-1465.

Sokol, P. A., Ohman, D. E. \& Iglewski, B. H. (1979). A more sensitive plate assay for detection of protease production by Pseudomanas aeruginosa. J Clin Microbiol 9, 538-540.

Taddei, F., Radman, M., Maynard-Smith, J., Toupance, B., Gouyon, P. H. \& Godelle, B. (1997). Role of mutator alleles in adaptive evolution. Nature 19, 700-702.

Tan, M. W., Mahajan-Miklos, S. \& Ausubel, F. M. (1999a). Killing of Caenorhabditis elegans by Pseudomonas aeruginosa used to model mammalian bacterial pathogenesis. Proc Natl Acad Sci U S A 96, 715-720.

Tan, M., Rahme, L. G., Sternberg, J. A., Tompkins, R. G. \& Ausubel, F. M. (1999b). Pseudomonas aeruginosa killing of Caenorhabditis 
elegans used to identify $P$. aeruginosa virulence factors. Proc Natl Acad Sci U S A 96, 2408-2413.

van Delden, C., Pesci, E. C., Pearson, J. P. \& Iglewski, B. H. (1998). Starvation selection restores elastase and rhamnolipid production in a Pseudomonas aeruginosa quorum-sensing mutant. Infect Immun 66, 4499-4502.

Vannini, A., Volpari, C., Gargioli, C., Muraglia, E., Cortese, R., De Francesco, R., Neddermann, P. \& Marco, S. D. (2002). The crystal structure of the quorum sensing protein TraR bound to its autoinducer and target DNA. EMBO J 17, 4393-4401.

Wagner, V. E., Bushnell, D., Passador, L., Brooks, A. I. \& Iglewski, B. H. (2003). Microarray analysis of Pseudomonas aeruginosa quorumsensing regulons: effects of growth phase and environment. J Bacteriol 185, 2080-2095.
Watson, B. T. C., Currier, M. P., Gordon, M. D., Chilton, E. \& Nester, W. (1975). Plasmid required for virulence of Agrobacterium tumefaciens. J Bacteriol 123, 255-264.

Whiteley, M., Lee, K. M. \& Greenberg, E. P. (1999). Identification of genes controlled by quorum sensing in Pseudomonas aeruginosa. Proc Natl Acad Sci U S A 96, 13904-13909.

Yates, E. A., Philipp, B., Buckley, C., Atkinson, S., Chhabra, S. R., Sockett, R. E., Goldner, M., Dessaux, Y., Camara, M. \& other authors (2002). $N$-Acylhomoserine lactones undergo lactonolysis in a $\mathrm{pH}$-, temperature-, and acyl chain length-dependent manner during growth of Yersinia pseudotuberculosis and Pseudomonas aeruginosa. Infect Immun 70, 5635-5646.

Edited by: S. Maclntyre 